\title{
ADHESION OF AN ENDODONTIC SEALER TO DENTIN AND GUTTA-PERCHA: SHEAR AND PUSH-OUT BOND STRENGTH MEASUREMENTS AND SEM ANALYSIS
}

\author{
Cleonice Silveira TEIXEIRA ${ }^{1,2}$, Edson ALFREDO ${ }^{2}$, Luis Henrique de Camargo THOMÉ $^{3}$, Ricardo GARIBA-SILVA ${ }^{2,3}$, \\ Yara T. Correa SILVA-SOUSA², Manoel Damião SOUSA-NETO ${ }^{3}$
}

1- DDS, MSc, PhD, Department of Stomatology, Dental School, University of Santa Catarina, Florianópolis, SC, Brazil.
2- DDS, MSc, PhD, Department of Endodontics, Dental School, University of Ribeirão Preto, Ribeirão Preto, SP, Brazil.
3- DDS, MSc, PhD, Department of Restorative Dentistry, Dental School of Ribeirão Preto, University of São Paulo, Ribeirão Preto, SP, Brazil.

Corresponding address: Prof. Dr. Manoel D. Sousa-Neto - Rua Célia de Oliveira Meireles, 350 - Jd. Canadá - 14024-070- Ribeirão Preto, SP - Brasil - Phone: +55-16-3623-6002 - Fax: +55-16-3602-3982 - e-mail: sousanet@forp.usp.br

Received: June10, 2008 - Accepted: September, 2008

\begin{abstract}
$T_{\text {he }}$

he use of an adequate method for evaluation of the adhesion of root canal filling materials provides more reliable results to allow comparison of the materials and substantiate their clinical choice. The aims of this study were to compare the shear bond strength (SBS) test and push-out test for evaluation of the adhesion of an epoxy-based endodontic sealer (AH Plus) to dentin and guttapercha, and to assess the failure modes on the debonded surfaces by means of scanning electron microscopy (SEM). Three groups were established $(n=7)$ : in group 1, root cylinders obtained from human canines were embedded in acrylic resin and had their canals prepared and filled with sealer; in group 2, longitudinal sections of dentin cylinders were embedded in resin with the canal surface smoothed and turned upwards; in group 3, gutta-percha cylinders were embedded in resin. Polyethylene tubes filled with sealer were positioned on the polished surface of the specimens (groups 2 and 3). The push-out test (group 1) and the SBS test (groups 2 and 3) were performed in an Instron universal testing machine running at crosshead speed of $1 \mathrm{~mm} / \mathrm{min}$. Means $( \pm \mathrm{SD})$ in MPa were: G1 (8.8 \pm 1.13$), G 2(5.9 \pm 1.05)$ and G3 (3.8 \pm 0.55$)$. Statistical analysis by ANOVA and Student's t-test $(\alpha=0.05)$ revealed statistically significant differences $(\mathrm{p}<0.01)$ among the groups. SEM analysis showed a predominance of adhesive and mixed failures of $\mathrm{AH}$ Plus sealer. The tested surface affected significantly the results with the sealer reaching higher bond strength to dentin than to guttapercha with the SBS test. The comparison of the employed methodologies showed that the SBS test produced significantly lower bond strength values than the push-out test, was skilful in determining the adhesion of AH Plus sealer to dentin and gutta-percha, and required specimens that could be easily prepared for SEM, presenting as a viable alternative for further experiments.
\end{abstract}

Key words: Adhesion. Push out test. Root canal sealer. Scanning electron microscopy. Shear bond strength.

\section{INTRODUCTION}

The endodontic treatment is completed by the threedimensional filling of the root canal system, which provides adequate sealing of the dentin structures after chemomechanical preparation. Root filling is achieved with the association of a solid filling material, such as gutta-percha or, more recently, Resilon ${ }^{\circledR 27,28}$ and a root canal sealer. Ideally, one of the key roles of the sealer is to aggregate the root filling material and maintain it as compact mass with no gaps, which adheres to the canal walls and provides a single block configuration that seals hermetically the canal space ${ }^{21}$. This adhesion process involves mechanical forces that yield the intertwining of the material with the dentin structure ${ }^{15}$ and may result in a greater sealing ability, thus reducing the risk of root canal microleakage and maintaining a cohesive filling $\operatorname{mass}^{20}$.

Several studies have investigated the adhesion of different types of root canal sealers to root dentin and guttapercha $^{4,11,19,20,22,24}$. Although the American Dental Association ${ }^{2}$ has issued a series of regulations and tests for study of the physical properties of root canal sealers, adhesion tests have not yet been standardized because no consensus on test parameters has been reached among researchers. Moreover, the divergent results obtained in the studies and the difficulties in testing materials with great plasticity, such as gutta-percha and Resilon ${ }^{\circledR}$, or materials with high modules of elasticity, such as radicular posts, have led to the development of different methodologies for determining the bond strength of endodontic sealers to coronal or root dentin ${ }^{7,9,10,24-26}$. Among the mechanical tests, stands out the shear bond strength (SBS) test, in which the force is applied parallel to the interface 
between the material and the tested surface ${ }^{5}$. This test has been used to measure the bond strength of endodontic sealers to dentin and gutta-percha or, more recently, for Resilon ${ }^{\circledR}$ and has been proven effective and reproducible $7,10,11,25,26$. On the other hand, the push-out test allows an accurate standardization of the specimens ${ }^{23,24}$ while the micro-pushout test, for use in smaller areas, yields the development of a more uniform shear strength without the interference of the tensile component, thus producing a stress more reliably

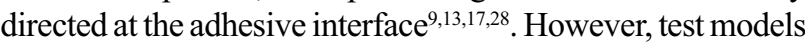
cannot reproduce the exact clinical conditions, mainly because root dentin is not uniform and the surface of the canal walls prepared during the endodontic treatment differ considerably ${ }^{21}$. Root canal dentin cylinders with a post spacelike cavity, as used in the push-out test $\mathrm{t}^{24}$, is an interesting option to test resin-based root canal sealers and radicular posts. Nevertheless, the use of flat root dentin surfaces would be a viable alternative to test resin materials ${ }^{5}$, as well as other materials with less cohesive strength, such as gutta-percha and non-resin sealers, allowing comparison of the results by the same methodology 25

The use of an adequate method for evaluation of the adhesion of root canal filling materials provides more reliable results to allow comparison of the materials and substantiate their clinical choice. Therefore, the primary goal of this study was to compare the SBS test and push-out test in their ability to measure accurately the bond strength of a resin-based endodontic sealer (AH Plus) to dentin and gutta-percha. The secondary goal of this study was to assess the failure modes on the debonded surfaces by scanning electron microscopy (SEM).

\section{MATERIAL AND METHODS}

Eleven extracted noncarious human maxillary canines were stored in $0.1 \%$ thymol diluted in saline at $4{ }^{\circ} \mathrm{C}$ and used within 3 months following extraction. The teeth were sectioned transversally at the cementoenamel junction and at the root tip with a low-speed diamond saw (Isomet; Buehler, Lake Bluff, IL, USA) to produce 7-mm root cylinders. Three groups were formed, according to the type of adhesion methodology and test surface, as follows: Group 1: push-out test, dentin; Group 2: SBS test, dentin; and Group 3: SBS test, guttapercha.

\section{Push-out test, Dentin (Group 1)}

Seven dentin cylinders were centered in aluminum rings (16 mm diameter; $7 \mathrm{~mm}$ height) and embedded in acrylic resin, with the coronal side turned upwards. The aluminum rings containing the dentin cylinders were placed in a parallelometer and their coronal and apical surfaces were flattened and made parallel, until a final height of $6.8 \mathrm{~mm}$ was obtained. Each specimen was mounted in a specific apparatus that maintained it in a vertical position, parallel to the long axis of the tooth and to the root canal (Figure 1). The root canal diameter was enlarged using a low-speed handpiece and a conical diamond bur (893-047; Brasseler, Savannah, GA, USA). The depth of penetration of the bur was determined by the tip of its active part, which was leveled with the specimen's surface, and a standard conical shape was prepared with the following dimensions: height $=6.80 \mathrm{~mm}$; larger diameter $=2.60 \mathrm{~mm}$; and smaller diameter $=1.90 \mathrm{~mm}$. During preparation, the canals were irrigated with distilled water. The root canals were filled with AH Plus endodontic sealer (Dentsply, De Trey GmbH, Konstanz, Germany) using a syringe, stored in a humidifier at $37^{\circ} \mathrm{C}$ for $24 \mathrm{~h}$ for complete sealer setting and thereafter dried and subjected to the pushout test (Figure 1).

A stainless steel support was used to hold the specimens (aluminum ring + dentin cylinder) in a universal testing machine (Model 4444; Instron Inc., Canton, MA, USA) equipped with a load cell of $2000 \mathrm{~N}$, and running at a crosshead speed of $1 \mathrm{~mm} / \mathrm{min}$, in such a way that the side with the

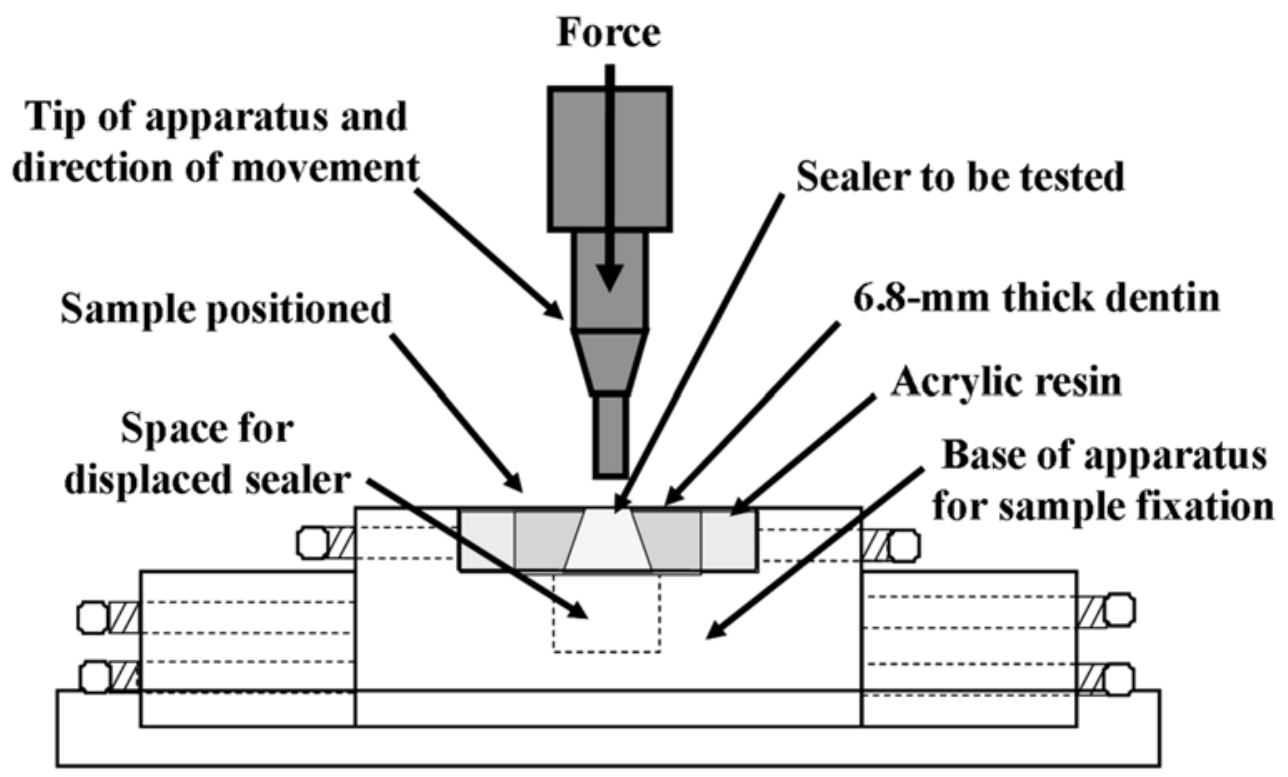

FIGURE 1- Schematic drawing of the push-out test 
smaller diameter of the root canal faced upwards and was aligned to the shaft that would exert pressure load on the sealer (apicocoronally). The tip of apparatus used for load application in the push-out test had diameter of $1.7 \mathrm{~mm}$; the smaller end of the dentin sample (where the tip was placed) was $1.9 \mathrm{~mm}$ in diameter, leaving a thin cement layer $(0.1$ $\mathrm{mm}$ ) surrounding the tip. This method assured the alignment of the specimen in a reproducible manner, and also avoided contact of the shaft with the dentin during testing. After pressure was applied, the load required to dislodge or fracture the sealer was recorded in $\mathrm{MPa}$.

\section{Shear bond strength test, dentin (Group 2)}

The remaining 4 dentin cylinders were sectioned longitudinally, producing 8 hemi-sections. One hemi-section was discarded and 7 hemi-sections were used for specimen preparation. The hemi-sections were centered in aluminum rings (diameter $=16 \mathrm{~mm}$ and height $=7 \mathrm{~mm}$ ) and embedded in acrylic resin with the root canal surface upwards. After resin polymerization, the dentin side of the specimens was ground with wet 100-grit sandpaper to flatten the surface and then submitted to 15-s polishing cycles with wet 180-, 220-, 300,400- and 600-grit sandpaper, sequentially. Polyethylene tubes (length $=7 \mathrm{~mm}$; inner diameter $=3 \mathrm{~mm}$; outer diameter $=4 \mathrm{~mm}$ ) were filled with AH Plus sealer (Dentsply, De Trey $\mathrm{GmbH}$, Konstanz, Germany) with a syringe and carefully placed with one open side contacting the polished flat dentin, perpendicular to its surface. The specimens were stored in a humidifier at $37^{\circ} \mathrm{C}$ for 24 hours, and thereafter dried and subjected to the SBS test.

A stainless steel support was used to hold the specimens that were screwed into the base and aligned with the loading axis of a Bencor Multi-T testing assembly (Danville Engineering, San Ramon, CA, USA). A wire loop prepared from a nylon thread ( $0.60 \mathrm{~mm}$ in diameter) was wrapped around the bonded assembly so that it was as close as possible to dentin (Figure 2), in such a way that the load would be applied with the least possible variations. The universal testing machine (Model 4444) was calibrated at crosshead speed of $1 \mathrm{~mm} / \mathrm{min}$ and a tensile load was applied to produce a shearing force that resulted in debonding of the root hemi-section along the AH Plus sealer interface. Interfacial shear strength was calculated by dividing the maximum load recorded on failure with the circular bonding area and expressed in $\mathrm{MPa}$.

\section{Shear bond strength test, gutta-percha (Group 3)}

Seven specimens were fabricated as follows: a red wax cylinder $($ diameter $=6 \mathrm{~mm}$ and height $=3 \mathrm{~mm}$ ) was centered in an aluminum ring (diameter $=16 \mathrm{~mm}$ and height $=7 \mathrm{~mm}$ ) and acrylic resin was poured over the wax until the cylinder was filled. After resin polymerization, the wax was removed and replaced by gutta-percha. Standardized size 80 cones of gutta-percha (Hygienic Corp., Akron, OH, USA) were softened by short immersion in a thermostat controlled water bath $\left(45 \pm 3^{\circ} \mathrm{C}\right)$, and compacted with a larger plugger into the previously described cavity. A glass plate was placed over this set until the gutta-percha hardened. The specimens were polished to ensure flattened surfaces in the same way as described for Group 2. Polyethylene tubes containing AH Plus sealer were centered on the gutta-percha and allowed to set as described above. Next, the specimens were dried and subjected to SBS test, as described for Group 2 (Figure 2).

\section{Specimen Preparation for Scanning Electron Microscopy Analysis}

The dentin cylinders from group 1 were sectioned longitudinally to its long axis to make possible the perpendicular analysis of dentin surface. In all groups, the debonded surfaces were dried, mounted on aluminum stubs, sputter-coated with gold/palladium (Bal-Tec SCD 005, BalTec Co., Balzers, Liechtenstein) and analyzed with a scanning electron microscope (Philips SEM XL 30; Philips, Eindhoven, The Netherlands) to determine the failure mode: adhesive (at dentin/sealer or gutta-percha/sealer interface), cohesive in the

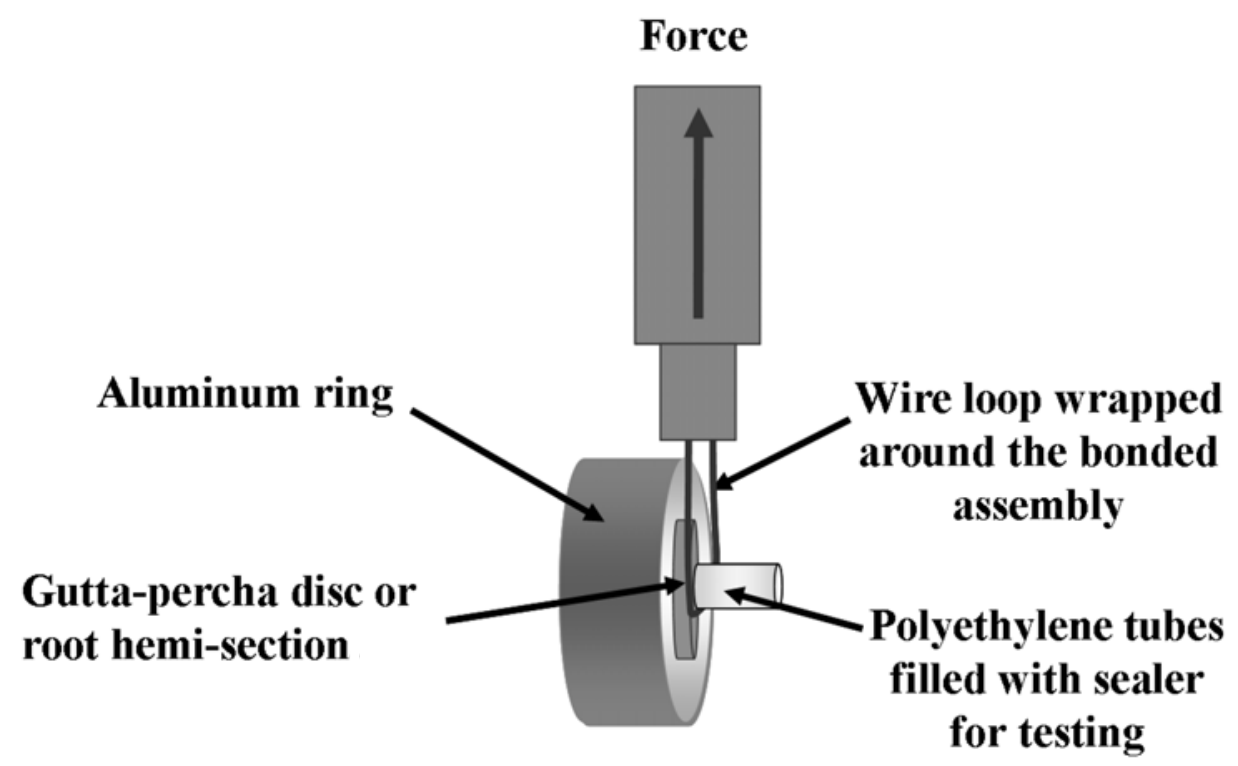

FIGURE 2- Schematic drawing of the SBS test. Placement of a nylon wire as close as possible to the gutta-percha disc or root hemi-section and stressing of the bonded assembly to failure in a universal testing machine 
sealer, and mixed (adhesive and cohesive) (11).

\section{Statistical Analysis}

In each set of data, the coefficient of variation was calculated as a parameter of consistency or reproducibility of the adhesion. Kolmogorov-Smirnov test was used to assess whether data distribution was normal. Bond strength means were analyzed statistically by the Student's t-test, with the significance level set at $\alpha=0.05$.

\section{RESULTS}

\section{Shear bond strength and push out tests}

For the tested methodologies, no early specimen failure was observed during sealer insertion and setting, prior to the tests. The results of the push-out and SBS tests are shown in Table 1. The Kolmogorov-Smirnov test revealed that data distribution was normal and the variation coefficients were $12.84 \%, 17.79 \%$ and $14.47 \%$ for groups 1,2 and 3 , respectively. There was statistically significant difference (Student's t-test; $P=0.0004$ ) between group 1 (push-out test/ dentin) and group 2 (SBS/dentin), the push-out test presenting higher mean. The type of tested surface also affected significantly the bond strength means (Student's t-test; $P=$ 0.0005 ), group 2 (SBS test/dentin) presenting higher mean than group 3 (SBS test/gutta-percha).

\section{SEM Analysis}

The results of the failure modes analysis are show in the Table 2. The analysis of the debonded surfaces by SEM revealed that, regardless of the tested surfaces (dentin or guttapercha), there was a predominance of the mixed failure mode (adhesive failure of the sealer on center of the specimen and cohesive failure on its borders) in the groups submitted to shear bond strength test (Figure 3A-D). For the specimens submitted to the push-out test, adhesive failures of the sealer were predominately observed. However, some specimens exhibited cohesive failures on the outer apical region (Figure 4A,B).

TABLE 1- Bond strength means (MPa) and standard deviations (SD) of AH Plus sealer to dentin after push-out test (G1) and to dentin and gutta-percha after SBS test (G2 and G3)

\begin{tabular}{lccc}
\hline Samples & $\begin{array}{c}\text { G1 } \\
\text { Push-out test/dentin }\end{array}$ & $\begin{array}{c}\text { G2 } \\
\text { SBS test/dentin }\end{array}$ & $\begin{array}{c}\text { G3 } \\
\text { SBS test/gutta-percha }\end{array}$ \\
\hline 1 & 8.9 & 7.2 & 4.4 \\
2 & 8.0 & 5.0 & 3.7 \\
3 & 9.8 & 4.7 & 3.6 \\
4 & 10.4 & 5.4 & 2.8 \\
5 & 7.5 & 6.0 & 3.6 \\
7 & 9.2 & 7.5 & 4.0 \\
Mean $\mathbf{S ~ S D}^{*}$ & 7.6 & 5.6 & 4.3 \\
\hline
\end{tabular}

*Different letters indicate statistically significant difference $(p<0.05)$

TABLE 2- Failure modes observed on the debonded specimens of the three experimental groups

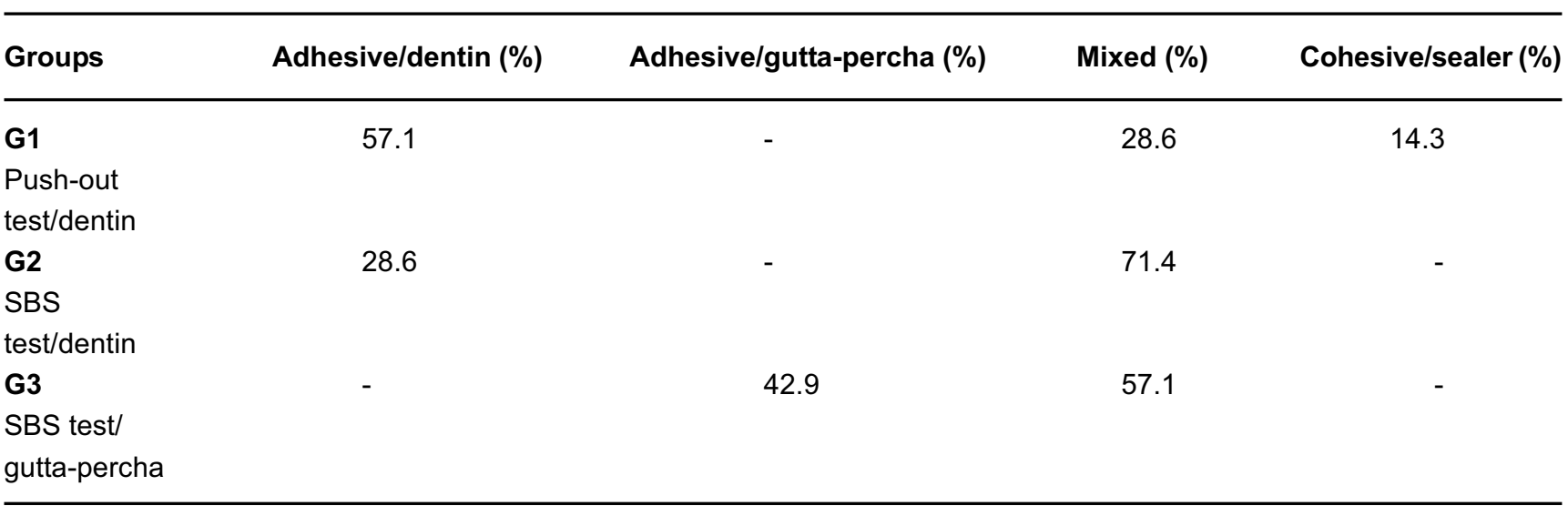




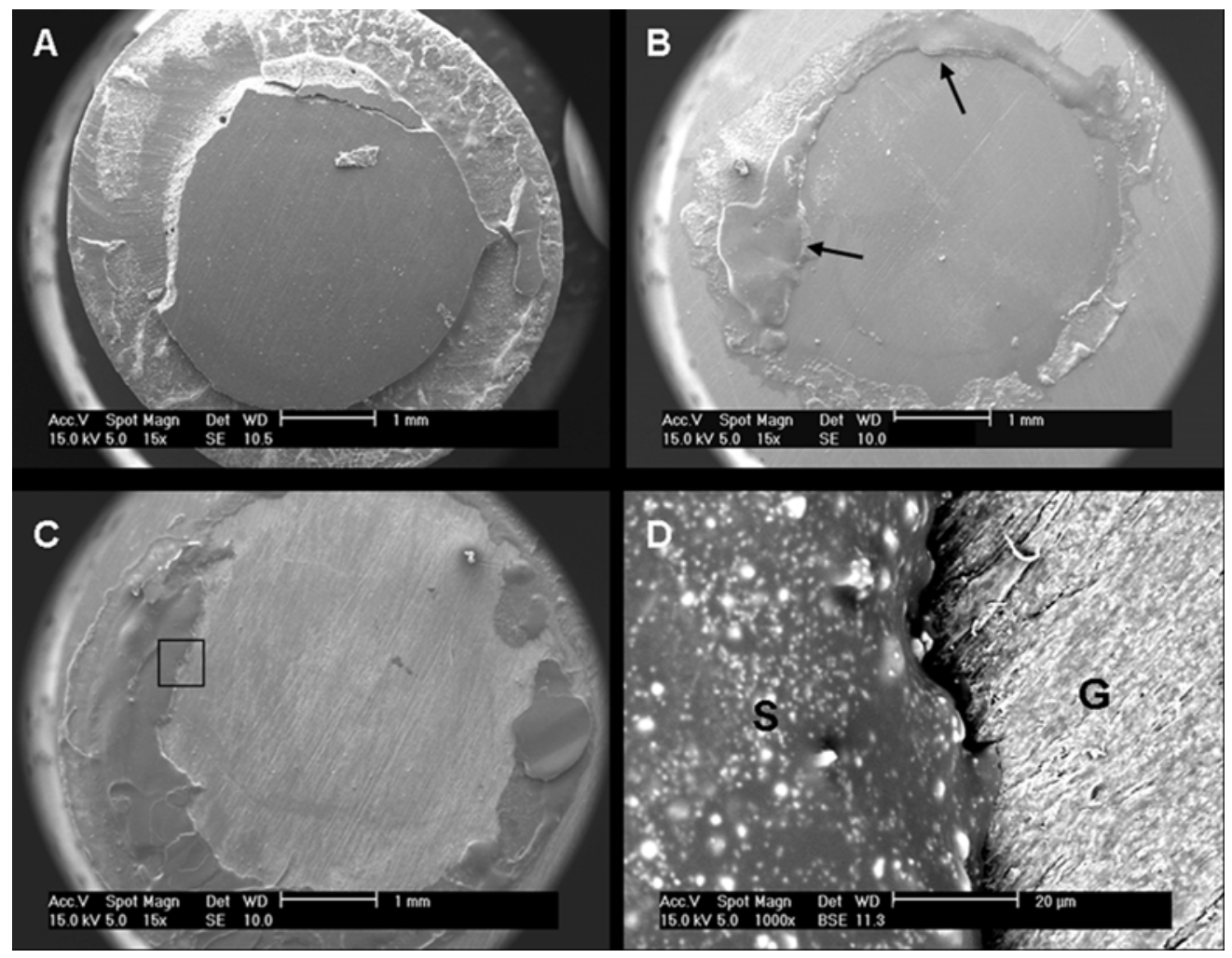

FIGURE 3- Representative debonded surfaces after SBS test. (A) AH Plus sealer with cohesive failure of the sealer close to the borders (SE, ×15). (B) Dentin surface exhibiting fractured cement (arrows) adhered to the surface (SE, $\times 15)$. (C) Surface of a gutta-percha specimen where mixed failure occurred, with sealer failure on the borders of the circle formed by the polyethylene tube $(S E, \times 15)$. (D) Greater magnification of the area delimited in C, confirming the presence of sealer remnants adhered to gutta-percha surface $(B S E, \times 1000)$. $S=$ AH Plus sealer, $G=$ gutta-percha

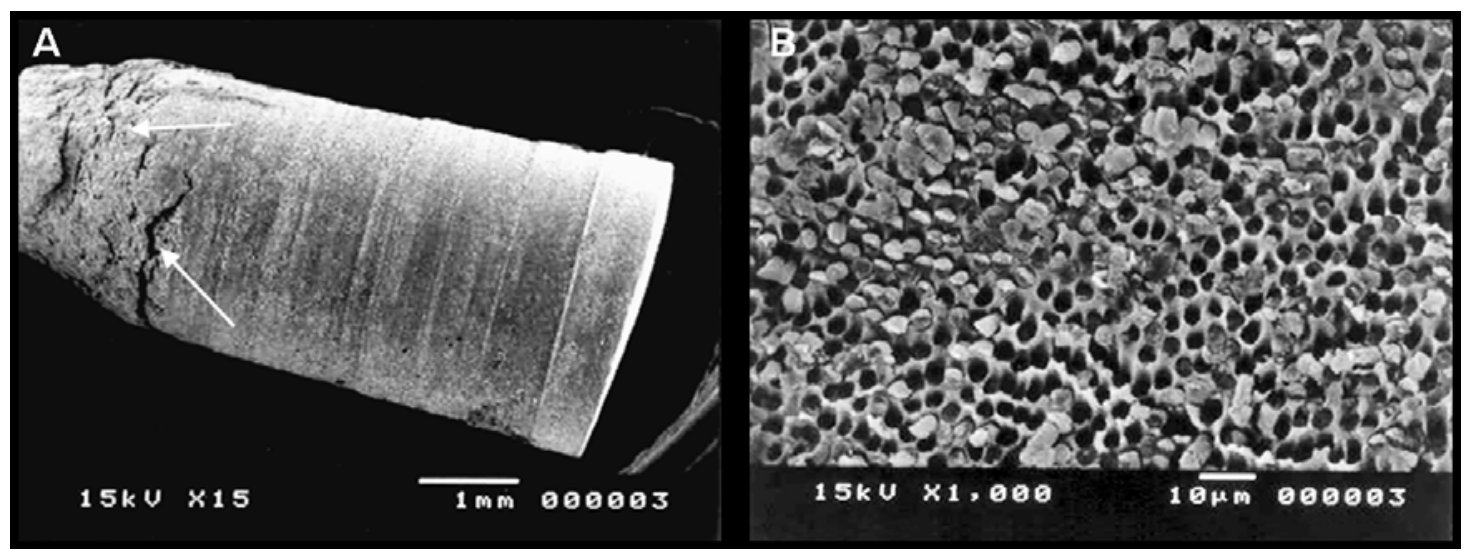

FIGURE 4- (A) Representative sample of $A H$ Plus sealer post after debonding by the push-out test. (SE, $\times 15)$. There was cohesive failure of the sealer on the outer apical region (arrows). (B) Representative dentin of the root canal, partly covered by sealer after the push-out test $(\mathrm{SE}, \times 1000)$

\section{DISCUSSION}

Bond strength of endodontic sealers to dentin and root canal filling material has been extensively investigated $^{7,14,18,19,20,24,25,30}$. Nevertheless, few studies have attempted to establish a methodology that would provide a more standardized test model, and overall investigated the adhesion of endodontic sealers to the coronal dentin rather than root dentin ${ }^{18,25,30}$. Other studies have tested coronal dentin discs cemented to gutta-percha discs ${ }^{14,20}$. However, not using root canal dentin for conduction of these tests could mask some results due to the structural differences between coronal and intra-radicular dentin ${ }^{6,15}$.

The primary objective of the present study was to compare the SBS test to the push-out test regarding their ability to measure accurately the bond strength of AH Plus resin-based sealer to dentin and gutta-percha. Therefore, unlike previous study models, the present work not only used root canal dentin (rather than coronal dentin), but also obtained results derived from the application of shearing forces (rather than tensile 
forces). In another study ${ }^{20}$ that evaluated the effect of dentin pretreatment on the adhesion of root canal sealers, the dentin/ sealer/gutta-percha interface was tractioned until failure with application of the tensile load in the same direction as that of the dentin tubules. In the present study, the load was applied perpendicular to the dentin tubules, which simulates the real forces that act inside the root canal ${ }^{24}$. Furthermore, the tensile bond strength test is more sensitive than the push-out test, in such a way that even small changes in the specimen or in stress distribution during load application affect significantly the results ${ }^{28,29}$

The push-out test used in this study was performed on specimens obtained from the cervical and middle root thirds of human canines. Others authors ${ }^{24}$ have pointed out the advantages of this method, including the possibility of placing the sealer in direct contact with the intracanal dentin walls, instead of a flat coronal dentin surface, which presents a different tubule arrangement pattern. Additionally, when the specimen is filled with sealer, the material accommodates to the canal shape and penetrates into the dentinal tubules, promoting mechanical retention similar to that of clinical conditions. However, this method is not advisable for plastic materials, such as gutta-percha or Resilon ${ }^{\circledR}$.

The use of SBS test with flat intra-radicular dentin specimens allows assessing the bond strength of materials with greater plasticity, such as gutta-percha. Another advantage of using flat surfaces is the ease of specimen standardization ${ }^{25}$, which allows comparing the bond strength of root canal sealers not only to dentin, but also to other root canal filling materials ${ }^{10}$. In the present study, flat surfaces were used to assess the SBS of AH Plus sealer to root canal dentin and gutta-percha.

On the other hand, a major problem of the shear testing is that it is difficult to align closely the shear-loading device with the adhesive interface 5 . If the load is offset away from the interface, a bending moment will be created which could cause some deviation in the results ${ }^{12}$. In this experiment, the use of a wire loop prepared with a nylon thread as close as possible to the tested interface (Figure 2) in order to apply the shear load with the least possible variations.

The bond strength means of AH Plus sealer obtained with the SBS test on flat surfaces (group 2/dentin or group 3/guttapercha) were lower than those recorded with the push-out test (group 1). AH Plus is an epoxy-based endodontic sealer that is used with gutta-percha in vertical or lateral compaction techniques. Although AH-Plus has adequate long-term dimensional stability, its sealing ability remains controversial partly because AH-Plus does not bond to gutta-percha. Despite this, AH Plus has been shown to provide adhesion to dentin and better long-term sealing ability due its reported expansion over time ${ }^{1,3,16}$. Even though the bond strengths were not very high in either of the methods used in this experiment, the low standard deviations indicate that the means recorded with both tests were homogeneous (Table 1). Moreover, our results are in agreement with those of previous studies that have reported low bond strengths for epoxy resin sealers to gutta-percha ${ }^{26,28}$ and dentin ${ }^{7,8,26,28}$.

A possible explanation for the higher bond strengths recorded with the push-out test (Group 1) compared to the SBS test with flat surfaces may be the shape of the cavity and the mode of specimen fabrication. The preparation of the canal space produces a series of variables that may affect the results, including $\mathrm{C}$ factor configuration and polymerization shrinkage of resin-based materials ${ }^{4,9,13,17}$. In the specimens subjected to the push-out test, canal preparation resulted in an approximately 7-mm deep confined cavity, and it may be hypothesized that the cavity shape may have exerted a friction effect on the sealer. According to another study ${ }^{9}$, friction has a significant role on the bond strength of cemented intraradicular posts. Likewise, it may be speculated that the sealer is also subjected to these friction forces in the push-out test.

During chemomechanical preparation of root canals, smear layer is formed on the dentin walls. Treatment of the intra-radicular dentin with chemicals that remove the smear layer, such as, ethylenediaminetetraacetic acid (EDTA) and sodium hypochlorite, may affect bond strength. While some studies have found higher bond strengths with AH Plus sealer when the smear layer was maintained ${ }^{20,25}$, others have reported higher bond strengths after smear layer removal ${ }^{7}$. Given that no surface treatment other than polishing, rinsing with distilled water and drying could be performed on the gutta-percha specimens, dentin surface was treated in the same way for standardization purposes.

It is important to emphasize that due to its resin nature, flow and long setting time, AH Plus sealer penetrates deeper into the surface microirregularities, as well inside the lateral root canals ${ }^{1}$. These properties lead to greater intertwining of the sealer with dentin structure, which, together with the cohesion among the cement molecules ${ }^{23}$, provides greater adhesiveness and resistance to dislodgment from dentin ${ }^{24}$. Further studies should investigate the influence of different surface pretreatments before sealer insertion and compare the methodologies used in this experiment.

The secondary objective of this study was to determine the failure modes after debonding. SEM analysis showed a predominance of adhesive or mixed failures. In most cases, the sealer was almost completely dislodged from the surface (dentin or gutta-percha). In the SBS test to flat surfaces (groups 2 and 3), the nylon wire loop located around the specimen (Figure 2) favored a more uniform distribution of the load applied during shearing rather than if the load would have been applied on a single point. Nevertheless, failure occurred on the sealer borders and sealer remnants were found on dentin surface in almost all debonded specimens (mixed failure). Close to the polyethylene tube, cohesive failure of the sealer was observed and adhesive failure occurred on the center of the material (Figure 3A,B). The analysis of specimens subjected to the push-out test revealed an adhesive failure mode in most part of the sealer cone after debonding. However, failure within the sealer (cohesive failure) was observed in the areas closer to the apex. In the same way as observed for the specimens submitted to SBS test on flat surfaces, the areas initially exposed to tensile loads seemed to produce cohesive failures in the sealer. Given that the debonding force exerted on the specimens in the push-out test was in the apical to coronal direction, it may be inferred 
that there was greater load distribution in the apical region, resulting in cohesive failure in the sealer in this area (Figure $4 \mathrm{~A}$ ) and part of the fractured sealer covering the dentin (Figure 4B).

\section{CONCLUSION}

In this study, the SBS test to root dentin was proved to be a feasible and reproducible method. Although it produced significantly lower bond strengths than the push-out method, SBS test was easier to perform, which allowed testing guttapercha and dentin specimens in a similar manner. Additionally, it provided homogenous results with considerably low variation of bond strength.

\section{REFERENCES}

1- Almeida JF, Gomes BP, Ferraz CC, Souza-Filho FJ, Zaia AA. Filling of artificial lateral canals and microleakage and flow of five endodontic sealers. Int Endod J. 2007;9:692-9.

2- ANSI/ADA Specification No. 57 Endodontic Sealing Material. Chicago, USA: ANSI/ADA, 2000

3- Bouillaguet S, Shaw L, Barthelemy J, Krejci I, Wataha JC. Long-term sealing ability of pulp canal sealer, AH-Plus, guttaFlow and epiphany. Int Endod J. 2008;41:219-26

4- Bouillaguet S, Troesch S, Wataha JC, Krejci I, Meyer J-M, Pashley, DH. Microtensile bond strength between adhesive cements and root canal dentin. Dent Mater. 2003;19:199-205.

5- Dickens SH, Milos MF. Relationship of dentin shear bond strengths to different laboratory test designs. Am J Dent. 2002;3:185-92.

6- Duke ES, Lindemuth J. Variability of clinical dentin substrates. Am J Dent. 1991;4:241-6.

7- Eldeniz AU, Erdemir A, Belli S. Shear bond strength of three resin based sealers to dentin with and without the smear layer. J Endod. 2005;31:293-

8- Gesi A, Raffaelli O, Goracci C, Pashley DH, Tay FR, Ferrari M. Interfacia strength of Resilon and gutta-percha to intraradicular dentin. J Endod. 2005;31:809-13.

9- Goracci C, Tavares AU, Fabianelli A, Monticelli F, Raffaelli O, Cardoso $\mathrm{PC}$, et al. The adhesion between fiber posts and root canal walls: comparison between microtensile and push-out bond strength measurements. Eur J Oral Sci. 2004;112:353-61.

10- Hiraishi N, Loushine RJ, Vano M, Chieffi N, Weller RN, Ferrari M, et al. Is an oxygen inhibited layer required for bonding of resin-coated guttapercha to a methacrylate-based root canal sealer? J Endod. 2006;32:42933 .

11- Hiraishi N, Papacchini F, Loushine RJ, Weller RN, Ferrari M, Pashley $\mathrm{DH}$, et al. Shear bond strength of Resilon to a methacrylate-based root canal sealer. Int Endod J. 2005;38:753-63

12- Kitasako Y, Burrow MF, Nikaido T, Harada N, Inokoshi S, Yamada T, et al. Shear and tensile bond testing for resin cement evaluation. Dent Mater. 1995;11:298-304
13- Kurtz JS, Perdigao J, Geraldeli S, Hodges JS, Bowles WR. Bond strengths of tooth-colored posts, effect of sealer, dentin adhesive, and root region. Am J Dent. 2003;16(Suppl):31A-36A

14- Lee KW, Williams MC, Camps JJ, Pashley DH. Adhesion of endodontic sealers to dentin and gutta-percha. J Endod. 2002;28:684-8.

15- Nakabayashi N, Pashley D. Hybridization of dental hard tissues. Chicago, IL: Quintessence; 2000.

16- Ørstavik D, Nordahl I, Tibballs JE. Dimensional change following setting of root canal sealer materials.Dent Mater. 2001;6:512-9.

17- Perdigão J, Gomes G, K. Lee IL. The effect of silane on the bond strengths of fiber posts. Dent Mater. 2006;22:752-8.

18- Picoli F, Brugnera-Junior A, Saquy PC, Guerisoli DM, Pecora JD. Effect of Er:YAG laser and EDTAC on the adhesiveness to dentine of different sealers containing calcium hydroxide. Int Endod J. 2003;36:472-5.

19- Saleh IM, Ruyter E, Nat R, Haapasalo PMP, Ørstavik D. Adhesion of endodontic sealers: scanning electron microscopy and energy dispersive spectroscopy. J Endod. 2003;29:595-601.

20- Saleh IM, Ruyter IE, Haapasalo M, Ørstavik D. The effects of dentine pretreatment on the adhesion of root canal sealers. Int Endod J. 200235:85966.

21- Schwartz RS. Adhesive dentistry and endodontics. Part 2: bonding in the root canal system-the promise and the problems: a review. J Endod. 2006;32:1125-34.

22- Sevimay S, Dalat D. Evaluation of penetration and adaptation of three different sealers: a SEM study. J Oral Rehabil. 2003;30:951-5.

23- Sousa-Neto MD, Marchesan MA, Pécora JD, Brugnera-Júnior A, SilvaSousa YTC, Saquy PC. Effect of Er:YAG laser on adhesion of root canal sealers. J Endod. 2002;28:185-7.

24- Sousa-Neto MD, Silva Coelho FI, Marchesan MA, Alfredo E, SilvaSousa YT. Ex vivo study of the adhesion of an epoxy-based sealer to human dentine submitted to irradiation with Er:YAG and Nd:YAG lasers. Int Endod J. 2005;38:866-70.

25- Tagger M, Tagger E, Tjan AHL, Bakland LK. Measurement of adhesion of endodontic sealers to dentin. J Endod. 2002;28:351-4.

26- Tagger M, Tagger E, Tjan AHL, Bakland LK. Shearing bond strength of endodontic sealers to gutta-percha. J Endod. 2003;29:191-3.

27- Teixeira FB, Teixeira EC, Thompson JY, Trope M. Fracture resistance of roots endodontically treated with a new resin filling material. J Am Dent Assoc. 2004;135:646-52.

28- Ungor M, Onay EO, Orucoglu H. Push-out bond strengths: the EpiphanyResilon endodontic obturation system compared with different pairings of Epiphany, Resilon, AH Plus and gutta-percha. Int Endod J. 2006;39:643-7.

29- Van Noort R, Cardew GE, Howard IC, Noroozi S. The effect of local interfacial geometry on the measurement of the tensile bond strength to dentin. J Dent Res. 1991;70:889-93.

30- WachlarowiczAJ, JoyceAP, Roberts S, Pashley DH. Effect of endodontic irrigants on the shear bond strength of epiphany sealer to dentin. J Endod. 2007;33:152-5. 